\title{
Partial lipoatrophy with insulin resistant diabetes and hyperlipidaemia (Dunnigan syndrome)
}

\author{
J BURN AND M BARAITSER \\ From The Hospital for Sick Children, Great Ormond Street, London WC1N 3JH.
}

SUMmaRY A family is presented in which at least five members in three generations suffered a characteristic syndrome of generalised lipoatrophy, sparing the head and neck, and muscle hypertrophy variably associated with high plasma insulin and lipid levels and insulin resistant diabetes. This pedigree contains the first documented affected male with the syndrome. The diagnosis is of practical importance since close medical supervision of asymptomatic gene carriers is likely to improve their prognosis. The findings in this family have relevance also to the study of insulin and lipid metabolism.

In 1974 Dunnigan et al $^{1}$ reported a unique dominantly inherited lipodystrophy, characterised by progressive fat atrophy, sparing the face but involving the trunk and limbs. Those who were affected had an insulin resistant diabetes mellitus, acanthosis nigricans, and type $\mathrm{V}$ hyperlipoproteinaemia with raised triglycerides. Two families with this combination were described.

Köbberling et $a l^{2}$ in 1975 reported a similar family. To date only females have been affected. In contrast, the better known recessive type of lipodystrophy, or Berardinelli syndrome, has an early childhood onset and the distribution of the fat atrophy includes the face. It affects males and females equally. We report a large family in which several members suffered from the syndrome described by Dunnigan et al. ${ }^{1}$ Although females predominate, a male is affected. The nature of the sex limitation is discussed, together with the likely nature and site of the underlying defect. The prognostic value of this diagnosis is emphasised; asymptomatic gene carriers in the family may be advised of the need for dietary modification to reduce lipid levels.

\section{Case reports}

CASE IV. 3 (FIG 1)

At the age of 20 years this subject sought the opinion of her general practitioner for a trivial illness. Her doctor noted that she was exceptionally muscular with a masculine body habitus and she was

Received for publication 27 November 1984. Revised version accepted for publication 7 March 1985 referred for further evaluation. She was found to be of normal intelligence though very sensitive about her appearance. She had broad shoulders, powerful hirsute arms and legs, and very prominent peripheral veins due to a lack of subcutaneous fat over her whole body apart from her face, which was round and full (fig 2). There was true muscular hypertrophy over and above the muscular definition due to the lack of fat. Mild acanthosis nigricans was evident in both axillae. Muscular power in her limbs was exceptional for a female, but on examination of her nervous system she was otherwise normal. Secondary sexual characteristics and breast development appeared normal but full examination of her genitalia was not possible.

Her blood sugar was normal but she had raised triglycerides at $1.9 \mathrm{mmol} / \mathrm{l}$ (normal range 0.35 to 1.0 $\mathrm{mmol} / \mathrm{l})$. Her cholesterol and blood sugar were normal but she had a raised serum insulin $>64$ $\mathrm{mmol} / \mathrm{l}$ (normal range 0 to $33 \mathrm{mmol} / \mathrm{l}$ ).

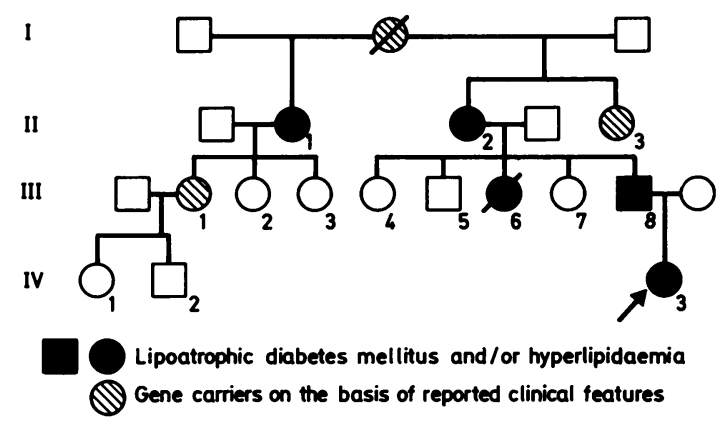

FIG 1 Family pedigree. 


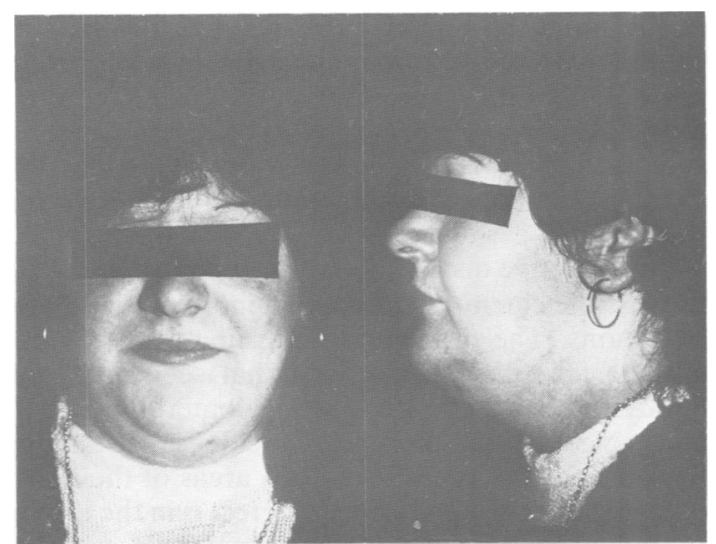

FIG 2 Subject IV.3. Note sparing of the face in patient with generalised lipodystrophy.

\section{CASE III.8 (FIG 1)}

The father was later examined. He was a 46 year old with no complaints, but had a history of left sided chest pain with radiation down his left arm. Throughout his adult life he had had a powerful physique but had made no particular effort to develop his musculature.

He had been investigated after presenting with the chest pain and had been found to have normal blood sugar and cholesterol levels. Repeat investigations after referral of his daughter revealed normal glucose and cholesterol levels but a raised triglyceride level of $6.7 \mathrm{mmol} / \mathrm{l}$ (range 0.3 to 1.7 $\mathrm{mmol} / \mathrm{l}$ ) and a raised insulin level of $>64 \mathrm{mmol} / \mathrm{l}$ (range 0 to $32 \mathrm{mmol} / \mathrm{l}$ ).

\section{CASE III.6 (FIG 1)}

This subject died at the age of 21 in severe left ventricular failure. She was known to have hyperlipidaemia and insulin resistant diabetes mellitus with hypertension. Control of her diabetes at first had been attempted by dietary measures followed by a variety of insulin regimens, but control had been poor. At the age of 18 she developed multiple eruptive xanthomata over the elbows and knees. At this stage her fasting cholesterol was $20.7 \mathrm{mmol} / \mathrm{l}$ (range 2.6 to $7.8 \mathrm{mmol} / \mathrm{l}$ ) with a triglyceride level of $21.8 \mathrm{mmol} / \mathrm{l}(0.3$ to $1.7 \mathrm{mmol} / \mathrm{l})$. At the age of 19 years her blood pressure was $220 / 150$, random blood sugar was $12.4 \mathrm{mmol} / \mathrm{l}(3.0$ to $5.0 \mathrm{mmol} / \mathrm{l})$, and cholesterol was $20.2 \mathrm{mmol} / \mathrm{l}$. Though her medical notes made no mention of her muscular build this was commented on by her brother and by other members of her family before her death.

CASE II. 1 (FIG 1)

In 1968 at the age of 38 years this subject presented with a complaint of polyuria and polydypsia and was found to be a diabetic and to have hyperlipidaemia. Examination revealed xanthomatous deposits in the skin of the left hand and elbow and larger subcutaneous deposits over the tibial tuberosities. She had an enlarged liver which at biopsy showed marked fatty change in hepatocytes around the centrilobular vein. The peripheral hepatocytes showed some degenerative changes. Her blood cholesterol was raised at $8.3 \mathrm{mmol} / \mathrm{l}$ with a triglyceride level of $7.2 \mathrm{mmol} / \mathrm{l}$ and lipoprotein strip which showed raised $\beta$ and pre- $\beta$ fractions. Subsequently medical attention was directed towards control of her diabetes with insulin and control of hypertension and raised lipids. Her response to various regimens has been partial. In 1980 she underwent surgery for peripheral vascular disease in both lower limbs. Her family had always noticed her exceptionally muscular build with sparing of her face.

\section{CASE II.2 (FIG 1)}

From pedigree data this woman was a gene carrier. Though no records were available, the notes of II.1 noted that her half sister suffered from hyperlipidaemia. II. 2 suffered from angina over a prolonged period and died after a cerebrovascular accident at 54 years of age.

\section{OTHER AFFECTED FAMILY MEMBERS}

The proband and her father had little difficulty identifying those affected on the basis of their muscular build and somewhat short stature; the proband was $152 \mathrm{~cm}$ and her father $163 \mathrm{~cm}$ tall.

\section{Discussion}

The present family both genetically and clinically have the same disorder as the family first reported by Dunnigan et al. ${ }^{1}$ They called it familial lipoatrophic diabetes mellitus with dominant transmission and drew attention to the clinical points of difference between this condition and the acquired and mostly sporadic adult onset lipoatrophic diabetes mellitus. They commented on the variability in severity of the syndrome which is evident in the family reported here. Of the four patients with well documented features of the condition one presented with clinical diabetes in middle life but was asymptomatic, and one presented with severe disease in adolescence which could not be adequately controlled and led to death at 21 years.

Despite the history in the latter cases the condition is relatively benign when compared to the Berardinelli syndrome, which is associated with generalised lipodystrophy and in which survival to 
middle life is unusual. Both of the families in Dunnigan's report came from the nearby towns of Dingwall and Inverness and the authors suggest a common genetic source. The family in the present report has no link with this area of Britain so it must be assumed it has arisen as a separate mutational event. The relationship between dominantly inherited lipoatrophic diabetes mellitus and the acquired type is uncertain. Dunnigan et $a l^{1}$ suggested that the points of difference are the presence of marked hepatomegaly, disturbed liver function tests, and kidney involvement in the acquired type. However, one of the patients in this report had a large liver with fatty infiltration and two of the four patients had severe hypertension. The points of similarity between the acquired lipoatrophic and familial type are that females are more commonly affected, both have raised triglycerides and cutaneous xanthomata, the clinical diabetes is generally insulin resistant and nonketotic, and there are raised plasma insulin levels. An important clinical difference is the sparing of the face in the familial type.

This family adds further weight to the impression of female preponderance, since there are five affected females and only one affected male. Davidson and Young ${ }^{3}$ reported eight females and Köbberling et $a l^{2}$ reported five affected females. The latter author in a personal communication to Wettke-Schafer and Kantner ${ }^{4}$ commented that affected women had to date produced 33 females to 19 males and it was suggested that the evidence was for $\mathrm{X}$ linked dominant inheritance with lethality in hemizygous males. The paucity of normal and affected males is still compatible with $\mathrm{X}$ linked dominant inheritance if one assumes the occurrence of early miscarriages which are not being detected and reported. Although it is postulated that the reason for the lethality in males is the severity of the abnormality in the hemizygous male, it may also be that the biochemical effects associated with the gene defect are a potent cause of abortion, but when this is survived effects on the male are relatively mild. It is of interest that the father in the present report was less severely affected than his sister and daughter. Another possible cause for the reduction in the number of affected males may be that the clinical feature of severe muscular hypertrophy is not regarded as dysmorphic in the male, but does attract attention in the female as does absence of subcutaneous fat. It is unlikely, however, that this can be the entire explanation for the observed disparity.

The selective distribution of the lipoatrophy could provide the clue to the primary abnormality in these conditions. The distribution affecting the body but not the face is the reverse of that seen in partial lipodystrophy associated with glomerulonephritis and suggests that there is some basic distinction between the fat tissue in the two areas of the body. It is proposed that the primary defect is in the insulin receptors on the subcutaneous lipid cells and that this defect is confined, in the dominant lipoatrophic diabetes mellitus syndrome, to the lipid cells from the neck down. Absence or defective function of the insulin receptors would result in the failure of uptake of lipids with consequent atrophy of the tissues and a tendency to raised serum levels of lipids. The failure of end organ response could account for the raised insulin levels and thereby the muscular hypertrophy, since insulin is a known anabolic agent. The persistent strain on the production of insulin is suggested to be the basis for the diabetes, though a progressive but slow deterioration of insulin receptors could also produce a severe insulin resistant diabetes.

\footnotetext{
References

1 Dunnigan MG, Cochrane M, Kelly A, Scott JW. Familial lipoatrophic diabetes with dominant transmission. $Q \mathrm{~J}$ Med 1974;49:33-48.

2 Köbberling J, Willms B, Kattermann R, Creutzfeldt W. Lipodystrophy of the extremities. A dominantly inherited syndrome associated with lipoatrophic diabetes. Humangenetik 1975;29:111-20.

${ }^{3}$ Davidson MB, Young RT. Metabolic studies in familial partial lipodystrophy of the lower trunk and extremities. Diabetologica 1975;11:561-8.

4 Wettke-Schafer R, Kantner G. X-linked dominant inherited disease with lethality in hemizygous males. Hum Genet 1983;64:1-23.
}

Correspondence and requests for reprints to Dr $M$ Baraitser, Clinical Genetics Unit, Institute of Child Health, 30 Guilford Street, London WC1N 1EH. 